\title{
Self, memory, and imagining the future in a case of psychogenic amnesia
}

Article

Accepted Version

Rathbone, C., Ellis, J., Baker, I. and Butler, C. (2015) Self, memory, and imagining the future in a case of psychogenic amnesia. Neurocase, 21 (6). pp. 727-737. ISSN 1465-3656 doi: https://doi.org/10.1080/13554794.2014.977923 Available at https://centaur.reading.ac.uk/37914/

It is advisable to refer to the publisher's version if you intend to cite from the work. See Guidance on citing.

To link to this article DOI: http://dx.doi.org/10.1080/13554794.2014.977923

Publisher: Taylor \& Francis

All outputs in CentAUR are protected by Intellectual Property Rights law, including copyright law. Copyright and IPR is retained by the creators or other copyright holders. Terms and conditions for use of this material are defined in the End User Agreement.

\section{www.reading.ac.uk/centaur}

\section{CentAUR}

Central Archive at the University of Reading

Reading's research outputs online 
Self, memory, and imagining the future in a case of psychogenic amnesia

Clare J. Rathbone' ${ }^{1}$ Judi A. Ellis ${ }^{2}$, Ian Baker ${ }^{3}$, \& Chris R. Butler ${ }^{3}$

${ }^{1}$ Oxford Brookes University, Department of Psychology, Oxford, UK

2University of Reading, School of Psychology and Clinical Language Sciences, Reading, UK

${ }^{3}$ University of Oxford, Nuffield Department of Clinical Neurosciences, Oxford, UK

Running head: PSYCHOGENIC AMNESIA, SELF, AND FUTURE COGNITIONS

Author note:

The authors wish to thank $\mathrm{JH}$ and his wife, and the control participants, for all the time and effort they generously gave in helping us with this research. This work was supported by the Economic and Social Research Council (ES/K000918/1) and the Medical Research Council (MR/K010395/1).

Address for Correspondence:

Clare J. Rathbone

Department of Psychology, Oxford Brookes University, Oxford, UK, OX3 0BP

Tel. $+44(0) 1865483772$

Email: crathbone@brookes.ac.uk 


\title{
PSYCHOGENIC AMNESIA, SELF, AND FUTURE COGNITIONS
}

\begin{abstract}
We report a case of psychogenic amnesia and examine the relationships between autobiographical memory impairment, the self, and ability to imagine the future. Case study JH, a 60 year old male, experienced a 6 year period of pervasive psychogenic amnesia covering all life events from childhood to the age of 53. JH was tested during his amnesic period and again following hypnotherapy and the recovery of his memories. JH's amnesia corresponded with deficits in self-knowledge and imagining the future. Results are discussed with reference to models of self and memory and processes involving remembering and imagining.

Key words: Psychogenic amnesia, Functional amnesia, Self, Identity, Autobiographical memory, Imagining the future
\end{abstract}




\section{PSYCHOGENIC AMNESIA, SELF, AND FUTURE COGNITIONS}

Self, memory, and imagining the future in a case of psychogenic amnesia

Psychogenic amnesia refers to autobiographical memory impairments that occur in the absence of structural brain damage. It is commonly viewed as the result of blocked access to preonset memories, which remain stored but are no longer explicitly accessible (Kopelman, 2000; Markowitsch et al., 1999). Thus, psychogenic amnesia is thought to reflect problems with retrieval, rather than encoding, of memories (Papagno, 1998; Tramoni et al., 2009). Although relatively rare, psychogenic amnesia has been the subject of much research interest. However, to date, very few studies have directly investigated the impact of psychogenic amnesia on constructs of self and ability to imagine the future - two areas that are central to current theories of autobiographical memory (e.g., Conway, 2005; Schacter \& Addis, 2007). We will provide a brief overview of psychogenic amnesia and present our reasons for investigating case study $\mathrm{JH}$, with specific reference to the self-memory relationship and imagining the future.

Several researchers have noted that it is often difficult to differentiate psychogenic from organic amnesia (e.g., Campodonico \& Rediess, 1996; Kopelman, 2000), however the hallmarks of psychogenic amnesia typically include absence of neurological disease or injury, and memory loss accompanied by a loss of personal identity (Kopelman, 2000). The period of amnesia can begin with a fugue state (although fugue states are an uncommon presentation of psychogenic amnesia; Staniloiu and Markowitsch, 2014), in which the patient is found wandering around with no knowledge of their own name or address (e.g., Glisky et al., 2004; Markowitsch \& Staniloiu, 2011). It is widely accepted that psychogenic fugue is a consequence of psychological trauma; patients presenting with fugue will typically have experienced stressful situations involving 


\section{PSYCHOGENIC AMNESIA, SELF, AND FUTURE COGNITIONS}

emotionally loaded events (Kopelman, 2002; Markowitsch \& Staniloiu, 2011). Furthermore, models of psychogenic amnesia proposed by Kopelman $(2000,2002)$ and Markowitch et al. (1999) highlight the role that emotional stressors may play in altering frontal function, thus blocking access to autobiographical memories.

Reported cases have shown a range of deficits, including loss of native language (Glisky et al., 2004), reduced verbal fluency (Papagno, 1998) and deficits in personal semantic memory (e.g., names of family members and addresses; De Renzi et al., 1997). Some cases demonstrate impaired memory for public events and famous faces (Fujiwara et al., 2008; Staniloiu \& Markowitsch, 2012; Tramoni et al., 2009) whilst in others this type of general knowledge is spared (Glisky et al., 2004; Hennig-Fast et al., 2008). The time to recovery usually spans a few days to several months (Stracciari, Fonti, \& Guarino, 2008), but there have been cases where memory loss has persisted for periods of several years (Campodonico \& Rediess, 1996; De Renzi et al., 1997; Tramoni et al., 2009).

\section{Psychogenic Amnesia and the Self}

Previous research has emphasized the importance of investigating the self in cases of psychogenic amnesia (e.g., Arzy et al., 2011; Hennig-Fast et al., 2008; Staniloiu, Markowitsch, \& Brand, 2010). Staniloiu et al., (2010) coined the term the 'constricted self' to highlight the impact that psychogenic amnesia has on the self, and Janet (1907, p. 23, cited in Markowitsch \& Staniloiu, 2011) described dissociation as "an inability of the personal self to bind together the various mental components in an integrated whole under its control.” Indeed, the ability to project the self into the past and future through mental time travel is core to experiencing the self as persisting through time (Wheeler, Stuss \& Tulving, 1997). Reinhold and Markowitsch (2007) described two cases showing pervasive amnesia for the whole lifespan. In spite of normal 


\section{PSYCHOGENIC AMNESIA, SELF, AND FUTURE COGNITIONS}

executive functions, both patients showed reduced performance in emotional processing and theory of mind tasks, and were described by themselves and relatives as emotionally detached. Reinhold and Markowitch (2007) suggested that this combination of emotional disregulation and autonoetic deficits (e.g., impairments imagining the self in the past, present and future; Tulving, 2005) may be at the heart of disruptions in autobiographical retrieval, and relate to altered selfrelated processing.

Although this previous work suggests that processes involving the self might be significantly altered in psychogenic amnesia (e.g., Reinhold \& Markowitch, 2007; Staniloiu et al., 2010), there has been little direct investigation of 'the self' in this patient group. Within the context of autobiographical memory, the self has been conceptualized as an executive function: the 'working self' (Conway, 2005). The working self is viewed as one component of the selfmemory system (SMS) which binds episodic, event-specific knowledge to semantic autobiographical facts about the self. According to Conway (2005), the SMS is highly goalrelated, with the working self raising the accessibility of memories that are congruent with the goals of the self and inhibiting memories that are incongruent. The SMS has been used as an explanatory framework for "motivated confabulation" (Conway \& Tacchi, 1996) as well as in recent cases of possible psychogenic amnesia. For example, Piolino et al., (2005) proposed that their case CL may have inhibited memories from earlier life as they were considered discrepant with the current, more positive goals of the self.

From a theoretical point of view, cases of psychogenic amnesia present a rare opportunity to investigate the self-memory relationship. In organic retrograde amnesia, personal identity and sense of self are typically preserved (Klein \& Lax, 2010; Rathbone, Moulin \& Conway, 2009). In contrast, loss of personal identity is a hallmark of psychogenic forms of amnesia (Kopelman, 


\section{PSYCHOGENIC AMNESIA, SELF, AND FUTURE COGNITIONS}

2000; Staniloiu et al., 2010). Furthermore, in many cases of organic amnesia episodic memories (e.g., specific memories of events lasting less than one day) are impaired, whilst semantic autobiographical facts (e.g., names of schools attended) are preserved (e.g., Rathbone, Moulin \& Conway, 2009; Wheeler \& MacMillan, 2001). Klein and colleagues have reported cases of organic amnesic patients who have severe semantic memory deficits but retain semantic knowledge of their own identity and demonstrate a preserved sense of self (Klein, Cosmides, Costabile \& Mei, 2002). Indeed, Klein and Lax (2010) suggest that semantic self-trait knowledge (e.g., being friendly) is the most resilient form of knowledge and frequently persists in spite of severe brain damage.

The literature thus suggests that, in cases of severe memory deficit, personal identity is not necessarily reliant on episodic or semantic memory processes (e.g., Klein et al., 2002). As in cases of organic amnesia, some patients with psychogenic amnesia have shown dissociations between semantic and episodic memory impairment. Markowitsch et al., (1999) defined the 'mnestic block syndrome' as a failure to access episodic autobiographical memories while semantic autobiographical memories remain largely intact (although see Fujiwara et al., 2008). In contrast, other cases have demonstrated deficits in both episodic and semantic components of autobiographical memory. For example, the patient reported by De Renzi et al. (1997) burst into tears when his grandson ran up to greet him, as he was distressed to find that he didn't recognize his own grandson and did not even recall having any grandchildren.

Although several studies have explored issues relevant to the self in psychogenic amnesia, very few have investigated the self directly. For example, Hennig-Fast et al. (2008) examined the self in terms of episodic and semantic autobiographical memories (both, by definition, self-related forms of knowledge) and through fMRI analysis of areas of the cortex 


\section{PSYCHOGENIC AMNESIA, SELF, AND FUTURE COGNITIONS}

involved in self-reflection, however they did not examine the self specifically. A central aim of the present study was to investigate the self in psychogenic amnesia. Thus, we adopted an openended measure of the self previously used to elucidate the self in a case of organic amnesia (Rathbone et al., 2009). This enabled a more thorough investigation of how the self is constructed and perceived in psychogenic amnesia.

\section{Psychogenic amnesia and imagining the future}

A second area little explored in psychogenic amnesia is the ability to imagine future events. A growing body of evidence from both patient and healthy populations suggests that remembering and imagining overlap in function (Klein et al., 2002; Schacter \& Addis, 2007; Spreng \& Levine, 2006; Tulving, 1985). However, there has been little investigation of ability to imagine the future in psychogenic amnesia. Staniloiu et al. (2010) and Staniliou and Markowitsch (2012) noted that autonoetic consciousness is often impaired in both psychogenic and organic amnesia, with patients rendered unable to plan for the future. Further, Reinhold and Markowitsch (2007) noted that psychogenic amnesia patient LM found it difficult to make plans for the future and decide what job training to undertake. However, in spite of the fact that many cases of organic amnesia have demonstrated paralleled impairments in imagining and remembering (e.g., Tulving, 1985; Klein et al., 2002), to our knowledge this area has not been empirically examined in a case of psychogenic amnesia.

\section{Aims}

The aims of this study were to investigate the construct of self and ability to imagine the future in a case of psychogenic amnesia. To investigate the self-memory relationship we used the IAM Task (I Am Memory Task; Rathbone et al., 2008) which examines the organization of memories relevant to core aspects of identity. Previous research using this task has shown that 


\section{PSYCHOGENIC AMNESIA, SELF, AND FUTURE COGNITIONS}

memories are clustered around periods of identity formation, in both healthy adults (Rathbone et al., 2008) and organic amnesia (Rathbone et al., 2009). Our aims here were to explore how the self is perceived in psychogenic amnesia, whether self-images (e.g., I am a father, I am hardworking) can be used to cue memories, and how self-images are maintained in the absence of autobiographical memories.

Further, we predicted that deficits in remembering would be paralleled by deficits in imagining the future, reflecting the findings in organic amnesia (e.g., Klein et al., 2002; Tulving, 1985) and other patient groups (e.g., depression, Williams et al., 1996). To examine these processes, we present data from pre- and post-recovery. This approach is relatively novel in the psychogenic amnesia literature, and it enabled us to explore whether processes involving the self and capacity to imagine the future were more impaired during the period of amnesia compared to following recovery. If self-related processing and/or imagination deficits are independent predisposing factors for psychogenic amnesia, one might predict that such deficits would persist after recovery from the amnesia.

\section{Case Report}

$\mathrm{JH}$ is a 60 year old right-handed male who, for a six year period, experienced a pervasive psychogenic retrograde amnesia that spanned back from age 53 to early childhood.

\section{Onset and Extent of Psychogenic Amnesia}

In July $2005 \mathrm{JH}$ was admitted to hospital with confusion and retrograde amnesia, having been found by police after being reported missing by his family. All investigations including routine blood tests, MR brain imaging, cerebrospinal fluid examination, and EEG were unremarkable. He was discharged home with no follow-up arranged. 


\section{PSYCHOGENIC AMNESIA, SELF, AND FUTURE COGNITIONS}

In August 2010, JH was referred to the Oxford Clinic for Cognitive Disorders by a psychiatrist for further investigation. At interview with co-author CRB, he reported a complete retrograde amnesia for his life before July 2005, saying that he could recall less than $1 \%$ of events from this period. In contrast, his recollection for events since July 2005, such as a recent holiday to Cyprus, was thought by the patient and his wife to be entirely normal. In addition to this autobiographical amnesia, JH described having had to re-learn what objects were (specifically mentioning not recognising fire engines) and stated that he did not recognise anyone he had not seen since before July 2005. From July 2005, he claimed he started to re-learn who people were, and reported only needing to see someone once for them to be remembered on subsequent occasions. It should be noted that $\mathrm{JH}$ reported that he had experienced this pervasive amnesia at a consistent level for the six year period between 2005 and 2011, during which time none of his friends or family members questioned its validity.

Although $\mathrm{JH}$ was unable to recall the period leading up to the onset of his amnesia, his wife reported that there had been a number of adverse life events, including major financial difficulties. The patient was assessed by a consultant liaison psychiatrist shortly after his initial presentation in 2005 , and followed up for one year. He was diagnosed with a 'functional retrograde amnesia'. He was initially treated with citalopram for a mild mood disorder but this was stopped after a few months as his mood was felt to have improved. He had a past history of depression with episodes of attempted suicide in 1984 and 2000. These episodes both occurred following significant adverse life events. Nevertheless, at the time of his referral in 2010, he was working full time (having returned to full time work 3-4 months after July 2005), drove a car and reported having no problems with activities of daily living. His sleep and appetite were normal 


\section{PSYCHOGENIC AMNESIA, SELF, AND FUTURE COGNITIONS}

and his mood was reported (by $\mathrm{JH}$ ) to be reasonable, although both he and his wife felt that he had become more irritable and less confident since the onset of amnesia.

Neuropsychological Tests. Table 1 shows JH's scores in a battery of neuropsychological tests that took place in June 2011, approximately six years after the onset of his amnesia.

Insert Table 1 about here

Generally, JH's neuropsychological test scores were in the normal range, matching those of six control participants (details of this control group appear below) and performing above average on the Stroop test. However, JH's scores on the Hospital Anxiety and Depression Scale (HADS; Zigmond \& Snaith, 1983) revealed a higher than average overall score and higher ratings than controls for both depression and anxiety sub-scores. According to recommended cutoffs (Zigmond \& Snaith, 1983) JH was in the normal range (below the optimal cut-off of 8/21) on the depression subscale and scored just above the cut off (also 8/21) for anxiety.

\section{Recovery of Autobiographical Memory}

Between October and November of 2011, JH had three sessions of hypnotherapy. Following these sessions, JH reported suddenly being able to remember previously inaccessible autobiographical memories. He has subsequently recognised people who had not been encountered since before 2005, for example, an old neighbour from childhood (during JH's period of amnesia he would not have recognised people known prior to 2005). It was beyond the scope of this paper to provide an extended discussion of the processes in JH's hypnotherapy sessions that might have helped him regain access to his past. Bell et al. (2011) discussed the role that hypnosis might play as a neurocognitive rehabilitation tool and we suggest that a review of cases where hypnosis has been used to treat psychogenic forms of amnesia would be of benefit to the field. 


\section{PSYCHOGENIC AMNESIA, SELF, AND FUTURE COGNITIONS}

\section{Methods}

At both time 1 (2011, pre-hypnotherapy) and time 2 (2012, post-hypnotherapy), JH was tested on the range of memory measures described below. Although formal memory verification was not conducted, JH's wife was present at all testing sessions and she did not raise doubts over the veracity of any of the memories JH generated. He had no history of confabulation. A sample of six male control participants, matched for age and years of education (mean age 61.33 years, $\mathrm{SD}=2.34$, range $=58-64 ;$ mean years of education $=11.33, \mathrm{SD}=1.21 ; \mathrm{JH}$ years of education $=$ 11) and recruited through psychology departments at two UK universities, were also tested on all measures apart from the Autobiographical Memory Interview. Additional tasks (unrelated to the current study's aims) were used to assess more public forms of long-term memory (Famous Faces, Famous Events, and the New Word Acquisition Task; for results see Supplementary Materials).

\section{Measures}

The Autobiographical Memory Interview (AMI; Kopelman, Wilson \& Baddeley, 1989) was used to assess JH's episodic and semantic autobiographical memory performance across the lifespan.

The Crovitz-Schiffman Test (Crovitz \& Schiffman, 1974) consisted of 20 memory cue words (e.g., car, horse) and 20 future event cue words (e.g., cat, lake). Memory and future event cues were matched for imagery, concreteness, emotionality and familiarity (Rubin \& Friendly, 1986). For each cue word, participants were asked to think of a specific memory (or future event), to generate a brief title, and to rate the event from 1 to $10(1=$ low; $10=$ high $)$ for vividness, emotionality, and how often the event was thought about (rehearsal). Finally, all events were dated according to the participants' age at the time of the event. 


\section{PSYCHOGENIC AMNESIA, SELF, AND FUTURE COGNITIONS}

The I Am Memory Task (IAM Task; Rathbone, Moulin \& Conway, 2008) probes identity and autobiographical memory. Participants generated up to four identity statements (e.g., I am a father) and then used these identities as memory cues. Each statement was used to cue up to eight episodic autobiographical memories. Finally, all memories and identities were dated by the participant (memories by age at event and identities by age when each identity was formed).

\section{Results}

\section{Autobiographical Memory Interview}

In order to assess the semantic and episodic components of autobiographical retrieval, JH completed the Autobiographical Memory Interview (AMI). JH's scores in the AMI are shown in Table 2.

Insert Table 2 about here

JH's scores indicate that in 2011 his total personal semantic memory score (e.g., across all lifetime periods) was 'definitely abnormal' (e.g., <47) and his total autobiographical incidents (e.g., episodic) memory score was at the low end of 'probably abnormal' (13-15). In the childhood lifetime period he scored as definitely abnormal for both semantic and episodic memory. In early adult life his semantic memory is definitely abnormal and his episodic memory is probably abnormal. In recent life he scored maximum marks across all scales and was thus in the normal range. In $2012 \mathrm{JH}$ 's scores are at the top end of the normal range across all lifetime periods for both semantic and episodic retrieval.

\section{Crovitz-Schiffman Task}

Results from the Crovitz-Schiffman Task enabled us to examine the features and distributions of JH's memories and imagined events (see Table 3).

Insert Table 3 about here 


\section{PSYCHOGENIC AMNESIA, SELF, AND FUTURE COGNITIONS}

JH's scores in 2011 and 2012 were compared to the control mean using z-scores. In 2011, $\mathrm{JH}$ generated fewer memories and fewer future events than controls. Memories that were generated were dated as closer to the present than controls' memories (reflecting JH's inability to access memories from prior to 2005). In 2012, JH performed at control level on the memory measures, but still generated fewer imagined future events than control participants, and rated his future events as less detailed and less emotional. We compared JH's future event ratings for vividness and emotionality between 2011 and 2012 using paired sample $t$ tests. There was no significant difference between JH's future event vividness ratings over time $(t[10]=1.75, p=$ .11), but his ratings for future event emotionality were significantly lower in 2012 than in 2011 $(t[10]=2.63, p=.03)$.

Using the age at event data, we were able to plot the distribution of JH's autobiographical memories and imagined future events across the lifespan. To account for JH's difference in age between 2011 and 2012 (and small differences between the ages of control participants), these data were reformulated to show distance from present. Distribution of both memories and future events are shown for $\mathrm{JH}$ in 2011, 2012, and for controls (see Figure 1).

Insert Figure 1 about here

Figure 1 shows that in $2011 \mathrm{JH}$ was unable to recall a single autobiographical event that took place more than 10 years ago (in fact, this truncation began at six years prior to the present - in 2005). This striking demonstration of JH's dense amnesia is in contrast to the typical pattern of lifespan retrieval, in which one would expect to see a reminiscence bump (e.g., increase in memories) during late adolescence and young adulthood (e.g., Rubin Wetzler \& Nebes, 1986). The control participants' data demonstrate such a reminiscence bump, shown by the increased proportion of memories dated in bin -41 to -50 (which approximately maps onto the participants' 


\section{PSYCHOGENIC AMNESIA, SELF, AND FUTURE COGNITIONS}

teenage years). As demonstrated in both the AMI and Crovitz-Schiffman Task, in $2011 \mathrm{JH}$ had severe autobiographical memory deficits. In light of the established link between autobiographical memory and the self, we were motivated to examine features of JH's identity.

\section{IAM Task}

In 2011, JH was instructed to generate four I am statements which were essential to defining who he was: 'I am a husband', 'I am a bampy' (grandfather), 'I am a DIY-er', and 'I am a family person'. He was then asked to provide eight autobiographical memories that he felt reflected each of the identity statements given. JH was able to think of eight memories only for his fourth statement 'I am a family person', generating between three and seven memories for each of the other three identity statements (recalling 23 of a possible 32 memories in total). All of these memories were dated within the previous six years (post-2005). Interestingly, when JH dated his identity statements (e.g., the age at which each of the four I am statements was formed), he chose to date all of these identities as beginning within the last six years. This was in spite of semantic knowledge about the 'objective' dates for several of these identities, for example, the fact that he became a husband thirty years ago (correctly dated in the 2011 AMI). To examine the temporal relationship between memories and identity, all memories were reformulated as a number of years before or after the formation of their related self. Thus, a memory from age 55 which related to 'I am a husband' (dated as being formed at age 53), would be reformulated as 2 . To account for missing data, these results were presented as proportions divided into eight 10-year bins (see Figure 2).

Insert Fig 2 about here 


\section{PSYCHOGENIC AMNESIA, SELF, AND FUTURE COGNITIONS}

Figure 2 reveals a temporal clustering of memories around the age at which $\mathrm{JH}$ judged his identities to have emerged when tested in 2011. However, JH's pervasive amnesia meant that any memories that were accessible would necessarily appear to cluster.

JH was retested on the IAM Task in 2012. On this occasion JH generated two new identity statements ('I am a father' and 'I am a salesman') and repeated two from 2011 ('I am a grandfather' and 'I am a family person'). JH was able to generate a full set of eight memories per identity, and dated these (and the identities that cued them) in a much wider distribution across the lifespan. It is notable that JH's memories in 2012 show a similar pattern to controls. Although there was not the expected prominence of memories in the central epoch (-4 years before identity formation to 5 years after), JH's memories were mostly dated within the twentyyear period that encompasses the four years prior to identity formation and the 15 years after.

The IAM Task also enables examination of the ages at which identities are dated as being formed across the lifespan. As described above, in $2011 \mathrm{JH}$ 's identities were all dated as formed (e.g., becoming a defining part of JH's identity) in his fifties. In contrast, in 2012, JH's pattern of self-formation was similar to controls with most identities dated as emerging in early adulthood (see Figure 3).

Insert Fig. 3 about here

\section{Discussion}

One of the primary aims of this study was to examine the self-construct in psychogenic amnesia. Our novel results demonstrate that JH's memory deficits also extended to memories associated with what JH considered to be the most important aspects of his identity. When prompted to generate self-cued autobiographical memories, JH was not able to produce as many of these memories as control participants. This suggests JH's ability to access information 


\section{PSYCHOGENIC AMNESIA, SELF, AND FUTURE COGNITIONS}

relating to his sense of self and identity was impaired. The deficits in JH's memory were paralleled by deficits in imagining future events; relative to controls, JH generated fewer future events to cue-words - although notably this reduced ability to imagine future events remained when JH was tested a second-time (post-hypnotherapy).

The fact that $\mathrm{JH}$ was able to generate a full set of 32 self-cued memories in the IAM Task following recovery (compared to 23 when amnesic) suggests that his access to highly selfrelevant memories was restored. Furthermore, post-recovery, JH's self-cued memories were organized in similar temporal clusters to controls (and previously published studies, e.g., Rathbone et al., 2008, 2009). In addition, post-recovery JH's identities were distributed across the lifespan in a similar pattern to controls and previous studies (Rathbone et al., 2008) with most identities formed in early adulthood.

JH's pattern of memory impairments allowed us to test theories about the relationship between the self and autobiographical memory. Memory is considered to play a fundamental role in supporting temporal self-continuity, with both episodic and semantic memories thought to play important roles in supporting the self (e.g., Prebble et al., 2013). Unlike cases of episodic amnesia (e.g., patient PJM, Rathbone et al., 2009), JH lacked access to both episodic and semantic autobiographical memory. In our 2009 paper, we speculated that PJM's sense of self was supported by her semantic memories - that they formed a scaffold for her self-knowledge. Patient JH's semantic deficits allowed us to develop this idea further.

Semantic autobiographical facts are considered essential in forming a scaffold on which to support more specific autobiographical memories. For example, Schacter (1982) referred to such facts as 'control elements', and, like Conway (2005), viewed these facts as the highest level of a hierarchy, organizing access to more specific episodic memories. In support of this account, 


\section{PSYCHOGENIC AMNESIA, SELF, AND FUTURE COGNITIONS}

semantic facts have been viewed as 'chapters' that organize a personal life story (Thomsen, Pillemer, \& Ivcevic, 2011), and guide access to episodic memories associated with specific selfimages (Rathbone et al., 2008). We might consider then, that JH lacked the identity-based semantic scaffolding with which to organise, and indeed access, his past.

Our data cannot address whether JH's episodic memory loss stemmed from loss of semantic facts about the self (e.g., viewing semantic facts as a scaffold necessary for episodic memory) or whether deficits in episodic memory led to an inability to retrieve semantic facts about the self. Indeed, the proposed bi-directional relationship between self and memory (Conway, 2005) makes these factors difficult to test experimentally. However, results from PJM and other cases of pure episodic memory loss (e.g., Wheeler and McMillan, 2001) suggest that loss of episodic memory does not necessarily lead to loss of semantic memory. Thus, it appears that JH's episodic memory deficits either resulted from a failure to recall semantic facts (e.g., the scaffolding account), or that an additional factor impacted on both his semantic and episodic memory systems.

In considering factors that might affect the autobiographical memory system more broadly, it is relevant to return to motivational accounts of autobiographical memory (e.g., Conway, 2005) and the hyper-suppression suggested to underlie psychogenic amnesia (Tramoni et al., 2009). Conway's (2005) Self-Memory System predicts that only memories that are congruent with the goals of the self are accessible. Thus if $\mathrm{JH}$ was significantly motivated to avoid recalling stressful life events (a hallmark of psychogenic amnesia, e.g., Kopelman, 2000), we might expect such memories to be inhibited at both the level of episodic recollection and semantic knowledge. In support of a motivated forgetting account, Tramoni et al. (2009) found 


\section{PSYCHOGENIC AMNESIA, SELF, AND FUTURE COGNITIONS}

that patient PP suppressed newly acquired information more frequently than controls, suggesting that psychogenic amnesia may result from a hyper-suppression of pre-onset memories.

The second aim of this study was to examine whether memory deficits in psychogenic amnesia would be paralleled by deficits in imagining the future. In line with results from other patient groups (e.g., Klein et al., 2002; Tulving, 1985; Williams et al., 1996), we found that JH produced fewer imagined future events than controls when tested during his amnesia (although events were rated similarly to controls). Somewhat surprisingly, following the recovery of his memories, JH still showed a reduced ability to imagine the future, generating fewer events and rating events as less vivid and less emotional compared to controls. One explanation for this could be the differences between processes involved in remembering and imagining. Schacter et al. (2012) noted that imagining future events involves higher cognitive demands than remembering past events, and cited studies showing deficits specific to imagining the future (compared to episodic remembering) in patient groups such as semantic dementia (Irish et al., 2012). It is thus possible that the construction of future events is more vulnerable to deficits than recollection of past events.

As we did not re-test JH's mood post-recovery we cannot rule out the possibility that he was experiencing a low level mood disorder, which may have impacted on his ability to imagine specific future events (e.g., Williams et al., 1996). King et al. (2011) found that patients with major depressive disorder were selectively impaired in their ability to imagine specific episodic events; generation of semantic facts about the future was unaffected. Thus, JH's ratings for emotionality and vividness post-recovery could indicate an underlying mood disorder or vulnerability factor. As reported in the case history, JH had a past history of depression and attempted suicide. JH's ability to project events into the future appeared somewhat stunted at 


\section{PSYCHOGENIC AMNESIA, SELF, AND FUTURE COGNITIONS}

both testing periods, with future events being dated as occurring on average only three years into the future. However, this pattern was mirrored in controls and reflects the temporal organization of imagined future events demonstrated in other studies (e.g., Chessel et al., 2014, Spreng \& Levine, 2006).

To enable a fuller examination of the impact of psychogenic amnesia on imagining the future, it would have been beneficial to gather data on JH's ability to imagine the future using a range of different tasks. For example, probing both public and private future events, as well as positive and negative future events. Fortunately for $\mathrm{JH}$, his psychogenic amnesia abated during the period in which we were testing him. We suggest that more detailed examination of processes involving future cognition and the self should be a priority when testing patients experiencing the symptoms of psychogenic amnesia. Furthermore, we were unable to directly test models of remembering and imagining, such as the constructive episodic simulation hypothesis (Schacter \& Addis, 2007), as when we first tested JH in 2011 he had six years of autobiographical memories to draw on. Thus, although many of JH's memories were inaccessible, he was still able to access a number of years' worth of memories when constructing future events. Testing a patient's ability to imagine the future when they are at an earlier stage of psychogenic amnesia (e.g., before many new memories have been laid down) could prove to be a fruitful method for examining models of imagining and remembering.

Finally, distinguishing between conscious and unconscious processes of memory inhibition is a critical issue (Kopelman et al., 1994). Performance that is below chance level is typically viewed as evidence of simulation or malingering (e.g., Lezak, 1995), but JH did not perform below chance on our tasks. Although we conducted no formal measures of malingering (and thus cannot rule it out entirely), JH's performance in the cognitive battery of tasks was 


\section{PSYCHOGENIC AMNESIA, SELF, AND FUTURE COGNITIONS}

equivalent to controls (suggesting he was not trying to feign general poor performance) and his behaviour did not in any way suggest that he was malingering. Notably, JH's amnesic period lasted for six years, and reportedly caused him and his family a great deal of distress. He returned to work soon after the onset of his amnesia and did not receive any disability benefits that might have provided an incentive to malinger. In light of these facts, it is our opinion that the amnesia was beyond JH's conscious control.

In conclusion, these findings suggest that the semantic and episodic memory impairments associated with psychogenic amnesia are related to deficits in self-knowledge and a reduced ability to imagine future events. The findings for imagining the future replicate results in patients with organic memory disorders (e.g., Tulving 1985, Klein et al., 2002), but this is the first study to demonstrate these effects in psychogenic amnesia. Further research tracking changes in selfknowledge over the course of memory impairment and recovery in this disorder will further elucidate the mechanisms underpinning the self-memory relationship. 


\section{PSYCHOGENIC AMNESIA, SELF, AND FUTURE COGNITIONS}

\section{References}

Arzy, S., Collette, S., Wissmeyer, M., Lazeyras, F., Kaplan, P. W., \& Blanke, O. (2011). Psychogenic amnesia and self-identity: a multimodal functional investigation. European Journal of Neurology, 18(12), 1422-1425.

Bell, V., Oakley, D. A., Halligan, P. W., \& Deeley, Q. (2011). Dissociation in hysteria and hypnosis: evidence from cognitive neuroscience. Journal of Neurology Neurosurgery and Psychiatry, 82(3), 332-339.

Campodonico, J. R., \& Rediess S. (1996). Dissociation of implicit and explicit knowledge in a case of psychogenic retrograde amnesia. Journal of the International Neuropsychological Society, 2(2), 146-158.

Chessel, Z., Rathbone, C. J., Souchay, C., Charlesworth, L., \& Moulin, C. J. A. (2014). Autobiographical memory, past and future events and self-images in younger and older adults. Self and Identity, 13(4), 380-397.

Conway, M. A. (2005). Memory and the self. Journal of Memory and Language, 53(4), 594-628.

Conway, M. A., \& Tacchi, P. C. (1996). Motivated confabulation. Neurocase, 2(4), 325-338.

Crovitz, H. F., \& Schiffman, H. (1974). Frequency of episodic memories as a function of their age. Bulletin of the Psychonomic Society, 4(NB5), 517-518.

De Renzi, E., Lucchelli, F., Muggia, S., \& Spinnler, H. (1997). Is memory loss without anatomical damage tantamount to a psychogenic deficit? The case of pure retrograde amnesia. Neuropsychologia, 35(6), 781-794.

Fujiwara, E., Brand, M., Kracht, L., Kessler, J., Diebel, A., Netz, J., \& Markowitsch, H. J. (2008). Functional retrograde amnesia: a multiple case study. Cortex, 44(1), 29-45. 


\section{PSYCHOGENIC AMNESIA, SELF, AND FUTURE COGNITIONS}

Glisky, E. L., Ryan, L., Reminger, S., Hardt, O., Hayes, S. M., \& Hupbach, A. (2004). A case of psychogenic fugue: I understand, aber ich verstehe nichts. Neuropsychologia, 42(8), 1132-1147.

Hennig-Fast, K., Meister, F., Frodl, T., Beraldi, A., Padberg, F., Engel, R. R., Reiser, M., Möller, H. J., \& Meindl, T. (2008). A case of persistent retrograde amnesia following a dissociative fugue: Neuropsychological and neurofunctional underpinnings of loss of autobiographical memory and self-awareness. Neuropsychologia, 46(12), 2993-3005.

Irish, M., Addis, D. R., Hodges, J., \& Piguet, O. (2012). Considering the role of semantic memory in episodic future thinking: evidence from semantic dementia. Brain, 135, 21782191.

Janet, P. (1907). The major symptoms of hysteria. New York, NY: Macmillan.

King, M. J., MacDougall, A. G., Ferris, S., Herdman, K. A., \& McKinnon, M. C. (2011). Episodic simulation of future events is impaired in patients with major depressive disorder. Psychiatry Research, 187(3), 465-467.

Klein, S. B., Cosmides, L., Costabile, K. A., \& Mei, L. (2002). Is there something special about the self? A neuropsychological case study. Journal of Research in Personality, 36(5), 490-506.

Klein, S. B., \& Lax, M. L. (2010). The unanticipated resilience of trait self-knowledge in the face of neural damage. Memory, 18, 918-948.

Kopelman, M. D. (2000). Focal retrograde amnesia and the attribution of causality: An exceptionally critical review. Cognitive Neuropsychology, 17(7), 585-621.

Kopelman, M. D. (2002). Disorders of memory. Brain, 125, 2152-2190. 


\section{PSYCHOGENIC AMNESIA, SELF, AND FUTURE COGNITIONS}

Kopelman, M. D., Christensen, H., Puffett, A., \& Stanhope, N. (1994). The great escape - a neuropsychological study of psychogenic amnesia. Neuropsychologia, 32(6), 675-691.

Kopelman, M. D., Wilson, B. A., \& Baddeley, A. D. (1989). The autobiographical memory interview - a new assessment of autobiographical and personal semantic memory in amnesic patients. Journal of Clinical and Experimental Neuropsychology, 11(5), 724744.

Lezak, M.D. (1995). Neuropsychological assessment. Oxford, UK: Oxford University Press.

Markowitsch, H. J., Kessler, J., Russ, M. O., Frolich, L., Schneider, B., \& Maurer, K. (1999). Mnestic block syndrome. Cortex, 35(2), 219-230.

Markowitsch, H. J., \& Staniloiu, A. (2011). Memory, autonoetic consciousness, and the self. Consciousness and Cognition, 20(1), 16-39.

Papagno, C. (1998). Transient retrograde amnesia associated with impaired naming of living categories. Cortex, 34(1), 111-121.

Piolino, P., Hannequin, D., Desgranges, A., Girard, C., Beaunieux, H., Giffard, N., \& Eustache, F. (2005). Right ventral frontal hypometabolism and abnormal sense of self in a case of disproportionate retrograde amnesia. Cognitive Neuropsychology, 22(8), 1005-1034.

Prebble, S., Addis, D. R., \& Tippett, L. J. (2013). Autobiographical memory and sense of self. Psychological Bulletin, 139, 815-840.

Rathbone, C. J., Moulin, C. J. A., \& Conway, M. A. (2008). Self-centered memories: The reminiscence bump and the self. Memory \& Cognition, 36(8), 1403-1414.

Rathbone, C. J., Moulin, C. J. A., \& Conway, M. A. (2009). Autobiographical memory and amnesia: using conceptual knowledge to ground the self. Neurocase, 15(5), 405-418. 


\section{PSYCHOGENIC AMNESIA, SELF, AND FUTURE COGNITIONS}

Reinhold, N., \& Markowitsch, H. J. (2007). Emotion and consciousness in adolescent psychogenic amnesia. Journal of Neuropsychology, 1, 53-64.

Rubin, D. C. \& Friendly, M. (1986). Predicting which words get recalled: measures of free recall, availability, goodness, emotionality, and pronunciability for 925 nouns. Memory \& Cognition, 14(1), 79-94.

Rubin, D. C., Wetzler, S. E., \& Nebes, R. D. (1986). Autobiographical memory across the adult lifespan. In D. C. Rubin (Ed.), Autobiographical memory (pp. 202-221). Cambridge: Cambridge University Press.

Schacter, D. L. (1982). Stranger behind the engram: theories of memory and the psychology of science. Hillsdale, NJ: Erlbaum.

Schacter, D. L., \& Addis, D. R. (2007). The cognitive neuroscience of constructive memory: remembering the past and imagining the future. Philosophical Transactions of the Royal Society of London. Series B: Biological Sciences, 362, 773-786.

Schacter, D. L., Addis, D. R., Hassabis, D., Martin, V. C., Spreng, R. N., \& Szpunar, K. K. (2012). The future of memory: remembering, imagining, and the brain. Neuron, 76, 677694.

Spreng, R. N., \& Levine, B. (2006). The temporal distribution of past and future autobiographical events across the lifespan. Memory \& Cognition, 34(8), 1644-1651.

Staniloiu, A., \& Markowitsch, H. J. (2012). Towards solving the riddle of forgetting in functional amnesia: recent advances and current opinions. Frontiers in Psychology, 3, 403.doi: 10.3389/fpsyg.2012.00403 


\section{PSYCHOGENIC AMNESIA, SELF, AND FUTURE COGNITIONS}

Staniloiu, A., \& Markowitsch, H. J. (2014). Dissociative amnesia. The Lancet Psychiatry, 1(3), 226-241. doi:10.1016/S2215-0366(14)70279-2

Staniloiu, A., Markowitsch, H. J., \& Brand, M. (2010). Psychogenic amnesia - A malady of the constricted self. Consciousness and Cognition, 19(3), 778-801.

Stracciari, A., Fonti, C., \& Guarino, M. (2008). When the past is lost: focal retrograde amnesia. Focus on the "functional" form. Behavioural Neurology, 20(3-4), 113-125.

Thomsen, D. K., Pillemer, D. B., \& Ivcevic, Z. (2011). Life story chapters, specific memories and the reminiscence bump. Memory, 19(3), 267-279.

Tramoni, E., Aubert-Khalfa, S., Guye, M., Ranjeva, J. P., Felician, O., \& Ceccaldi, M. (2009). Hypo-retrieval and hyper-suppression mechanisms in functional amnesia. Neuropsychologia, 47(3), 611-624.

Tulving, E. (1985). Memory and consciousness. Canadian Psychology, 26, 1-12.

Tulving, E. (2005). Episodic memory and autonoesis: Uniquely human? In H. S. Terrace, \& J. Metcalfe (Eds.), The Missing Link in Cognition (pp. 4-56). NewYork, NY: Oxford University Press.

Wheeler, M. A., \& McMillan, C. T. (2001). Focal retrograde amnesia and the episodic-semantic distinction. Cognitive, Affective, \& Behavioral Neuroscience, 1(1), 22-36.

Wheeler, M. A., Stuss, D. T., \& Tulving, E. (1997). Toward a theory of episodic memory: The frontal lobes and autonoetic consciousness. Psychological Bulletin, 121(3), 331-354.

Williams, J. M. G., Ellis, N. C., Tyers, C., Healy, H., Rose, G., \& MacLeod, A. K. (1996). The specificity of autobiographical memory and imageability of the future. Memory \& Cognition, 24(1), 116-125. 


\section{PSYCHOGENIC AMNESIA, SELF, AND FUTURE COGNITIONS}

Zigmond, A. S., \& Snaith, R. P. (1983). The hospital anxiety and depression scale. Acta Psychiatrica Scandinavica, 67(6), 361-370. 
PSYCHOGENIC AMNESIA, SELF, AND FUTURE COGNITIONS

Table 1: Neuropsychological Test Results

\begin{tabular}{|c|c|c|c|}
\hline Test & $\begin{array}{c}\text { JH score in } \\
2011\end{array}$ & $\begin{array}{c}\text { Control Mean } \\
\text { (SD) }\end{array}$ & Max \\
\hline WAIS Block design & 40 & $34.2(10.31)$ & 51 \\
\hline Vocabulary word list & 50 & $47.6(11.13)$ & 70 \\
\hline NART & 44 & $36.6(9.94)$ & 50 \\
\hline CERAD 1 (immediate recall) & 0.77 & $0.55(0.14)$ & 1 \\
\hline Stroop simple (in 60 seconds) & $100 *$ & $76.5(9.19)$ & $\mathrm{n} / \mathrm{a}$ \\
\hline Stroop interference (in 60 seconds) & $45^{*}$ & $38(1.41)$ & $\mathrm{n} / \mathrm{a}$ \\
\hline Trails A & 20 & $36.8(9.68)$ & $\mathrm{n} / \mathrm{a}$ \\
\hline Trails B & 45 & $77.4(21.59)$ & $\mathrm{n} / \mathrm{a}$ \\
\hline CERAD 2 (delayed recall) & 0.6 & $0.32(0.18)$ & 1 \\
\hline CERAD 2 (recognition) & 1 & $0.92(0.06)$ & 1 \\
\hline MMSE & 27 & $26.2(2.59)$ & 30 \\
\hline Verbal fluency (letter: F) & 15 & $14.2(3.27)$ & $\mathrm{n} / \mathrm{a}$ \\
\hline Verbal fluency (category: animals) & 21 & $19.2(2.77)$ & $\mathrm{n} / \mathrm{a}$ \\
\hline Number copying (in 120 seconds) & 200 & $188.2(15.43)$ & $\mathrm{n} / \mathrm{a}$ \\
\hline Nottingham Ext. Activities of daily life & 20 & $22(0)$ & 22 \\
\hline
\end{tabular}


PSYCHOGENIC AMNESIA, SELF, AND FUTURE COGNITIONS

\begin{tabular}{lccc} 
HADS total score & $13^{*}$ & $3.6(3.13)$ & 42 \\
HADS anxiety items & $9 *$ & $2.4(2.70)$ & 21 \\
HADS depression items & $4^{*}$ & $1.2(0.45)$ & 21 \\
\hline
\end{tabular}

* JH's z-score was more than 2 standard deviations from the mean. N.b. The Stroop tests were only completed by two controls. All other tests scores include five of the six controls. 
PSYCHOGENIC AMNESIA, SELF, AND FUTURE COGNITIONS

Table 2: Autobiographical Memory Interview Scores for JH in 2011 and 2012

\begin{tabular}{|c|c|c|c|c|}
\hline \multirow[t]{2}{*}{ Lifetime Period } & \multicolumn{2}{|c|}{$\begin{array}{l}\text { Personal Semantic Score } \\
(\max 21 \text { in each period) }\end{array}$} & \multicolumn{2}{|c|}{$\begin{array}{l}\text { Autobiographical Incidents Score } \\
\text { (max } 9 \text { in each period) }\end{array}$} \\
\hline & 2011 (time 1) & 2012 (time 2) & 2011 (time 1) & 2012 (time 2) \\
\hline Childhood & 8 & 20 & 0 & 8 \\
\hline Early adult life & 14 & 21 & 4 & 8 \\
\hline Recent life & 21 & 21 & 9 & 9 \\
\hline Total & 43 & 62 & 13 & 25 \\
\hline
\end{tabular}


PSYCHOGENIC AMNESIA, SELF, AND FUTURE COGNITIONS

Table 3: Mean memory ratings (and standard deviations) using Crovtiz-Schiffman task for Control group and JH in 2011 and 2012

\begin{tabular}{|c|c|c|c|}
\hline & $\mathrm{JH}$ & $\mathrm{JH}$ & Control Group \\
\hline & 2011 & 2012 & Mean (SD) \\
\hline \multicolumn{4}{|l|}{ Memories } \\
\hline $\mathrm{N}$ & $16^{*}$ & 18 & $19.33(1.21)$ \\
\hline Vividness & $7.44(2.68)$ & $7.94(2.01)$ & $7.25(0.82)$ \\
\hline Emotionality & $8.06(2.43)$ & $5.83(2.83)$ & $5.46(1.37)$ \\
\hline Regularity of Recall & $3.38(2.03)$ & $1.83(1.15)$ & $2.78(0.62)$ \\
\hline Age at event & $55.14(1.83)$ & $34.89(16.07)$ & $35.41(10.62)$ \\
\hline Distance from present & $-3.86(1.83)^{*}$ & $-25.11(16.07)$ & $-26.09(10.81)$ \\
\hline \multicolumn{4}{|l|}{ Future Events } \\
\hline $\mathrm{N}$ & $13^{*}$ & $15^{*}$ & $18.50(1.38)$ \\
\hline Vividness & $7.23(2.28)$ & $5.53 *(2.20)$ & $7.31(0.45)$ \\
\hline Emotionality & $6.46(2.82)$ & $3.93 *(2.49)$ & $6.44(1.24)$ \\
\hline Regularity of Recall & $4.08(2.18)$ & $3.27(2.60)$ & $4.29(0.99)$ \\
\hline Age at event & $62.31(2.69)$ & $63.07(2.22)$ & $65.42(2.90)$ \\
\hline Distance from present & $3.31(2.69)$ & $3.07(2.22)$ & $3.92(1.47)$ \\
\hline
\end{tabular}




\section{PSYCHOGENIC AMNESIA, SELF, AND FUTURE COGNITIONS}

* JH's z-score was more than 2 standard deviations from the mean.

N.b. For ratings of vividness, emotionality and regularity of rehearsal, rating scores are from 1 (low) to 10 (high); age at event and distance from present were measured in years. 


\section{PSYCHOGENIC AMNESIA, SELF, AND FUTURE COGNITIONS}

\section{Figure captions}

Figure 1: Proportional lifespan distribution of memories (upper panel) and future events (lower panel) retrieved in Crovitz-Schiffman Task in controls, JH in 2011, and JH in 2012

Figure 2: Distribution of memories around identity formation in controls, JH in 2011, and JH in 2012 (Error bars show standard error)

Figure 3: Age of self-formation across the lifespan in controls, JH in 2011, and JH in 2012 